Iğdır Üniversitesi Fen Bilimleri Enstitüsü Dergisi, 11(1): 548-562, 2021

Journal of the Institute of Science and Technology, 11(1): 548-562, 2021

ISSN: 2146-0574, eISSN: 2536-4618

Makine Mühendisliği / Mechanical Engineering

DOI: $10.21597 /$ jist.789612

Derleme Makalesi / Review Article

Geliş tarihi / Received: 02-09-2020

Kabul tarihi / Accepted: 24-11-2020

Magnezyum ve Alaşımlarının Otomotiv Endüstrisindeki Önemi ve Uygulamaları

Fevzi KELEN ${ }^{1 *}$

ÖZET: Dünya petrol rezervlerinin hızla tükenmesi, artan yakıt ekonomisi talepleri ve egzoz emisyon değerlerine getirilen yasal sınırlamalar otomotiv endüstrisini modern hafif yapılara yönlendirmiştir. Otomobillerde kütle azaltımı ile hem yakıt verimliliğinin sağlanması hem de yanma sonucu açığa çıkan zararlı egzoz emisyonlarının en aza indirgenmesi hedeflenmiştir. Bu bağlamda üstün özelliklere sahip malzemelere ihtiyaç duyulmuştur. Magnezyum ve alaşımları düşük yoğunluk, yüksek özgül dayanım, kolay geri kazanım ve mükemmel sönümleme kapasitesi gibi karakteristik özellikleri ile otomotiv uygulamaları için en dikkat çekici yapısal malzemeler olarak ön plana çıkmaktadır. Bu malzemeler otomobillerin iç donanım, karoseri, şasi, güç aktarma organları ve araç ön alanı gibi temel sistem ve bileşenlerinde kullanılarak ağırlıkta önemli bir kazanım sağlayabilir. Böylece gerek yakıt sarfiyatı gerekse de insan sağlı̆̆ı ve çevre kalitesi açısından ciddi tehdit unsuru oluşturan egzoz emisyonları minimize edilebilir. Bu çalışmada, magnezyum ve alaşımlarının otomotiv endüstrisindeki önemine, mevcut ve olası uygulamalarına dikkat çekilmek istenmiştir.

Anahtar Kelimeler: Magnezyum ve alaşımları, Hafif alaşım ve kompozitler, Otomotiv malzemeleri

\title{
Importance and Applications of Magnesium and Its Alloys in Automotive Industry
}

ABSTRACT: Rapid depletion of world oil reserves, increasing fuel economy demands and legal restrictions on exhaust emission values have been led the automotive industry to modern lightweight structures. With the mass reduction in automobiles, it is aimed both to ensure fuel efficiency and to minimize harmful exhaust emissions caused by combustion. In this context, materials that have been superior properties are needed. Magnesium and its alloys come into prominence as the most remarkable structural materials for automotive applications with their characteristics like low density, high specific strength, easy recovery and excellent damping capacity. These materials can provide a significant gain in the weight by using them in the basic systems and components of automobiles such as interior equipment, the body of vehicles, chassis, powertrain and vehicle frontal area. Therefore, both exhaust emissions which pose a serious threat to human health and environmental quality, and fuel consumption can be minimized. In this study, it is aimed to draw attention to the importance, current and possible applications of magnesium and its alloys in the automotive industry.

Keywords: Magnesium and its alloys, Lightweight alloys and composites, Automotive materials

1Fevzi KELEN (Orcid ID: 0000-0003-3900-4503), Van Yüzüncü Y11 Üniversitesi, Van Meslek Yüksekokulu, Motorlu Araçlar ve Ulaştırma Teknolojileri Bölümü, Van, Türkiye

*Sorumlu Yazar/Corresponding Author: Fevzi KELEN, e-mail: fkelen@yyu. edu.tr 


\section{GíRiș}

Magnezyum $1.738 \mathrm{~g} \mathrm{~cm}^{-3}$ yoğunluğu ile tüm yapısal malzemeler arasında en hafif olanıdır. Magnezyum, alüminyumdan $\% 36$, demirden ise $\% 78$ daha hafiftir. $\mathrm{Bu}$ malzemeler düşük yoğunluklarının yanı sıra yüksek özgül dayanım, kolay geri kazanım, mükemmel sönümleme kapasitesi, yüksek 1s1 ve elektrik iletkenliği ve iyi döküm kabiliyeti gibi üstün özelliklere sahiptir (Gaines ve ark., 1996, Kainer ve Von Buch, 2003, Sankaranarayanan ve Gupta, 2020, Li ve ark., 2020). Bu özellikler ile magnezyum ve alaşımları otomotiv uygulamaları için önemli bir potansiyel oluşturmaktadır. Zira hafifliğin kritik bir parametre olduğu bu uygulamalarda taşıt kütlesi azaltılarak hem yakıt sarfiyatı hem de karbondioksit salınımının asgari düzeye çekilmesi planlanmıştır. Yakıt verimliliğini geliştirmede motor ve transmisyon verimliliğinin artırılması, aerodinamik tasarım, motor bloğu ve taşıt ön alanının küçültülmesi, motor, transmisyon ve lastiklerdeki sürtünmelerin en aza indirgenmesi gibi müteaddit parametre olmasına rağmen en etkili ve en ekonomik yöntem otomobil ağırlığının azaltılmasıdır. Lâkin yakıt tüketiminin ortalama \%75 gibi büyük bir bölümünün doğrudan taşıt kütlesinden kaynaklandığ1 düşünülmektedir (Davis, 1991, McWilliams, 2011, Kumar ve ark., 2020). Şekil 1'de taşıt kütlesi ile yakıt tüketimi arasındaki bağıntı verilmiştir. Bu grafikten de anlaşılabileceği üzere otomobil ağırlığında meydana gelen azalma, yakıt ekonomisine önemli bir katkı sağlamaktadır. Araç ağırlığında \%10'luk bir hafifleme ile yakıt tüketiminde \%8'e kadar bir iyileşme elde edilebilmektedir. Taşıt kütlesindeki 1 kg'lık azalma karbondioksit üretiminde $20 \mathrm{~kg}$ 'lık bir düşüş meydana getirmektedir. Ayrıca taşıt ağırlığının azalması yakıt sarfiyatı ve karbondioksit salınımını minimize etmenin yanı sıra ivmelenme, frenleme ve manevra kabiliyetlerini de iyileştirmektedir (Eliezer ve ark., 1998, Ghassemieh, 2011, Joost ve Krajewski, 2017). Öte yandan spesifik mukavemet çelik ve alüminyum alaşımlarına kıyasla magnezyum ve alaşımlarında çok daha yüksektir. Magnezyumun özgül dayanımı alüminyumdan $\% 14.075$, demirden ise \%67.716 daha büyüktür. Doğal hammadde ve enerji kaynaklarının korunması kapsamında geri dönüşebilirlik otomotiv endüstrisi için büyük önem arz etmektedir. Zira Avrupa Birliği üretilen taşıtlarda sarf edilen malzemelerin en az \%95'inin geri dönüşebilir olmasını hedefler iken Çin Halk Cumhuriyeti ise imal edilen araçlarda minimum \%95 oranında geri dönüşebilir malzeme kullanımını zorunlu kılmıştır. Ayrıca magnezyum ve alaşımlarının otomobillerde kullanımını cazip kılan diğer bir faktör motorun çalışması esnasında oluşan gürültü, titreşim ve düşük ataleti soğuracak yüksek sönümleme kapasiteleridir. Bu avantajlar magnezyum ve alaşımlarını otomotiv uygulamaları için ideal bir malzeme olarak ön plana çıkartmaktadır. Bu malzemeler otomobillerin iç donanım, karoseri, şasi, güç aktarma organları ve araç ön alanı gibi temel sistem ve bileşenlerinde geleneksel malzemelerin yerine tercih edilerek ağırlıkta çelik ve dökme demirlere göre $\% 75$, alüminyum ve alaşımlarına nazaran ise $\% 35$ oranlarında önemli bir kazanım sağlayabilir (Powers, 2000, Hanko ve ark., 2002, Dobrzanski ve ark., 2005, Kulekci, 2008, Wang ve Chen, 2013).

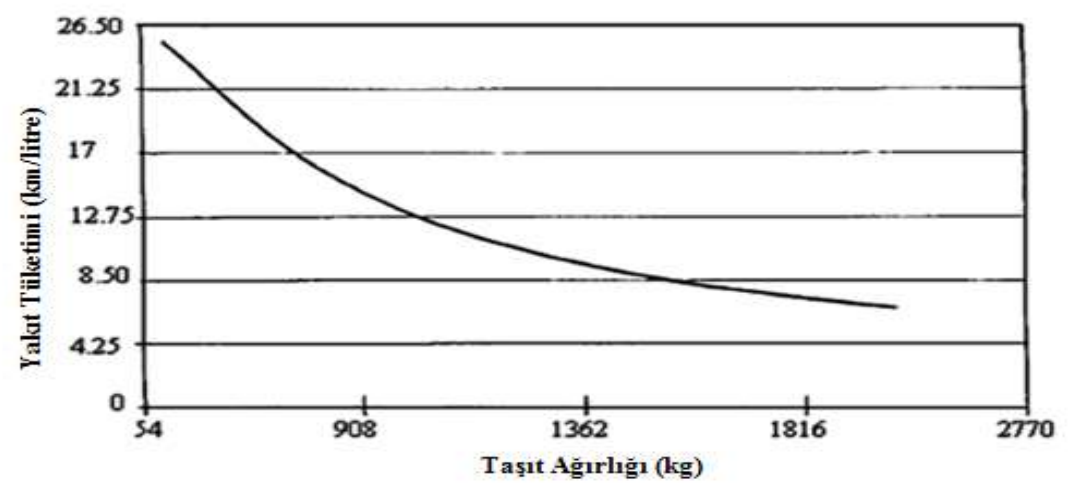

Şekil 1. Araç ağırlığı ile yakıt ekonomisi arasındaki bağıntı (Eliezer ve ark., 1998). 


\section{Genel Özellikler}

1755 'te İskoç kimyager Joseph Black tarafindan keşfedilen magnezyum adını Latince bir kelime olan magnesia'dan almaktadır. Yerkürede en fazla bulunan sekizinci element olup yer kabuğunun ortalama \%2'sini, okyanusların ise \%0.13'ünü oluşturmaktadır. Son derece reaktif bir element olan magnezyum altmıştan fazla mineral içerisinde bulunmasına karşın sadece dolomit $(\mathrm{MgCO} 3 * \mathrm{CaCO} 3)$, magnezit $(\mathrm{MgCO} 3)$, bischofite $(\mathrm{MgCl} 2 * 6 \mathrm{H} 2 \mathrm{O})$, karnalit $\left(\mathrm{MgCl} 2 * \mathrm{KCl}^{*} 6 \mathrm{H} 2 \mathrm{O}\right)$, serpentin (3MgO*2SiO2*2H2O) ve deniz suyu (Mg2+(aq)) ticari öneme sahiptir (Kramer, 2001, Harbodt, 2006, Aghion ve Golub, 2006). Çizelge I ve II' de fiziksel ve mekaniksel özellikleri sırası ile verilen saf magnezyumun kullanımı metalürjik prosesler ile sınırlıdır. Magnezyum ve alaşımları düşük yoğunluk, yüksek spesifik mukavemet, kolay geri kazanım ve yüksek sönümleme kapasitesi gibi önemli avantajlara sahip olmalarına karşın düşük elastisite modülü, zayıf korozyon dayanımı ve düşük süneklik gibi dezavantajlar bu malzemelerin endüstride alüminyum ve demire göre daha az tercih edilmesine neden olmuştur (Kainer ve Von Buch, 2003, Wang ve ark., 2018). Bu bağlamda magnezyum ve alaşımlarının düşük mekanik özelliklerini ve zayıf korozyon dayanımını iyileştirmek için birçok farklı alaşım elementi kullanılmıştır.

Çizelge I. Saf magnezyumun fiziksel özellikleri (Kainer ve Von Buch, 2003).

\begin{tabular}{ll}
\hline Kristal Yapı & $\mathrm{HSP}$ \\
Yoğunluk & $1.738 \mathrm{~g} \mathrm{~cm}^{-3}$ \\
Young Modülü & $45 \mathrm{GPa}$ \\
Çekme Dayanımı & $80-180 \mathrm{MPa}$ \\
Kırılma Uzaması & $\% 1-12$ \\
Erime Noktası & $650+/-0.5^{\circ} \mathrm{C}$ \\
Kaynama Noktası & $1090{ }^{\circ} \mathrm{C}$ \\
Özgül Isı & $1.05 \mathrm{~kJ} / \mathrm{kg} \cdot \mathrm{K}$ \\
Ergime Isısı & $195 \mathrm{~kJ} / \mathrm{kg}$ \\
Isıl İletkenlik & $156 \mathrm{~W} / \mathrm{m} \cdot \mathrm{K}$ \\
Doğrusal Genleşme Katsayısı & $26 \cdot 10^{-6} \mathrm{~K}-1$ \\
Çekme (Katı-Sıv1) & $\% 4.2$ \\
Elektrik İletkenliği & $22.4 \mathrm{~m} \cdot \Omega \mathrm{mm}^{2}$ \\
\hline
\end{tabular}

Çizelge II. Saf magnezyumun oda sıaklığı mekanik özellikleri (Westengen ve Aune, 2006).

\begin{tabular}{cccccc}
\hline Üretim Yöntemi & $\begin{array}{c}\text { Akma Mukavemeti } \\
\text { (Çekme) MPa }\end{array}$ & $\begin{array}{c}\text { Akma Mukavemeti } \\
\text { (Basma) MPa }\end{array}$ & $\begin{array}{c}\text { Çekme Mukavemeti } \\
\text { MPa }\end{array}$ & $\begin{array}{c}\text { Süneklik\% } \\
\text { Sertlik (Brinell) } \\
\text { HB }\end{array}$ \\
\hline Kum Döküm & 21 & 21 & 90 & $2-6$ & 30 \\
Ekstrüzyon & $69-105$ & $34-55$ & $165-205$ & $5-8$ & 35 \\
Levha (Haddelenmiş) & $115-140$ & $105-115$ & $180-220$ & $2-10$ & $45-47$ \\
Levha (Tavlanmış) & $90-105$ & $69-83$ & $160-195$ & $3-15$ & $40-41$ \\
\hline
\end{tabular}

Yaygın olarak kullanılan alaşım elementlerinden alüminyum, magnezyum alaşımlarının mukavemet, sertlik, dökülebilirlik ve korozyon dayanımını artırmasına karşın süneklik ve darbe dayanımını olumsuz etkilemektedir. Özellikle ara yüzeyde oluşan $\beta$-Mg17Al12 intermetalik faz nedeniyle sürünme dirençleri yetersizdir. Kalsiyum korozyon ve sürünme dayanımını geliştirirken alaşımın akıcılığını düşürmektedir. Magnezyum içerisinde sınırlı çözünürlüğe sahip olan mangan, alüminyum ve çinko içeren alaşımların korozyon direncini geliştirmektedir. Seryum, gadolinyum, neodimyum ve itriyum gibi nadir toprak elementleri mukavemet ve sürünme dayanımını iyileştirmelerine rağmen yüksek maliyetlerinden dolayı kullanımları oldukça sınırlıdır (Schwam ve ark., 2000, Mordike ve Lukac, 2006, Yim ve ark., 2006, T. Abu Leil, 2009, Mendis ve Hono, 2013, Sun ve ark., 2017, Tang ve ark., 2017, Song ve ark., 2020). Silisyum, toryum, stronsiyum ve zirkonyum gibi elementler yüksek sıcaklık mekanik özelliklerini, gümüş ise oda sıcaklığı dayanımını artırmaktadır. 
Ayrıca bu alaşım elementlerinden stronsiyum ve zirkonyum, çinko gibi tane inceltici etkiye sahip olup, alaşımın dökülebilirliğini geliştirmektedir. Öte yandan silisyum malzemenin sünekliğini olumsuz etkiler iken gümüş ve toryum ise ekonomik değildir (Li ve ark., 1993, Luo ve Pekguleryuz, 1994, Zhang, 2000, Mordike ve Buch 2003, Baril ve ark., 2003, Polmear, 2006, King, 2006). Şekil 2'de çeşitli alaşım elementlerinin saf magnezyum metalinin gelişimi üzerindeki etkisi gösterilmektedir. Magnezyum alaşım serilerinden AZ91, AM50 ve AM60, kolay dökülebilirlik, mükemmel sönümleme kapasitesi, nispeten yüksek dayanım ve iyi süneklilik özelliklerinden dolayı otomotiv endüstrisinde yaygın olarak tercih edilmektedir. Bunlar otomobillerde koltuk çerçevesi, direksiyon sistemi ve gösterge paneli gibi iç donanım bileşenlerinin imalatında kullanılmaktadır. AE44 ve AJ62 alaşımları yüksek sıcaklıklarda iyi mukavemet, QE22, WE42 ve WE54 serileri ise yeterli sürünme direnci sergilemektedir. Ayrıca AS41 ve AE42 alaşımları, $150^{\circ} \mathrm{C}$ sıcaklığa kadar yeterli sürünme dayanımı göstermektedir (Blum ve ark., 2000, Smola ve ark., 2004, Han ve ark., 2004, Westengen ve Aune, 2006, Watarai, 2006, Hussein ve Northwood, 2014). Yüksek sıcaklık dayanımları ve sürünme dirençleri otomobil güç aktarma organları uygulamaları için yeterli olan bu alaşım serileri taşıt ağırlığının önemli bir bölümünü oluşturan silindir bloğu, transmisyon ve diferansiyel kutusu gibi temel bileşenlerin üretiminde çelik ve alüminyum gibi geleneksel malzemelerin yerine tercih edilerek araç ağırlığında önemli kazanım elde edilmesini sağlayabilir.

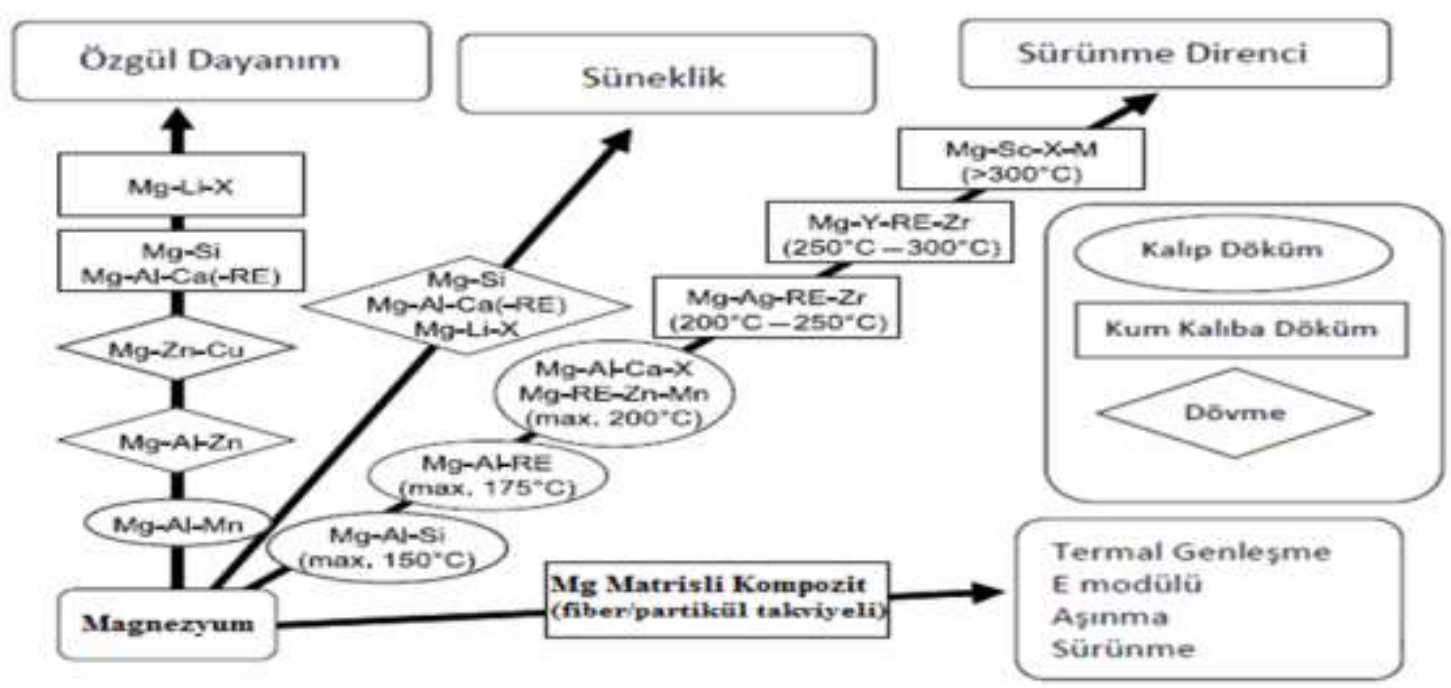

Şekil 2. Çeşitli alaşım elementlerinin saf magnezyum metalinin gelişimi üzerindeki etkisi (Mordike ve Lukac 2006).

\section{Üretim Yöntemleri}

Endüstriyel kullanımından bu yana devam eden alaşım geliştirme çalışmaları genellikle çeşitli alaşım elementlerinin birbiri ile etkileşimi ve bunların meydana getirdiği bileşimlerin farklı imalat teknikleri üzerine yoğunlaşmıştır. Magnezyumun kristal yapısından dolayı plastik deformasyon kabiliyeti son derece kısıtlıdır. Bu nedenle magnezyum ve alaşımlarının önemli bir kısmı döküm yöntemleri ile üretilmektedir. Genellikle basınçlı döküm, kokil kalıba döküm, kum kalıba döküm ve yarı-katı döküm metotları kullanılmaktadır. Döküm yöntemlerinin diğer proseslerden daha çok tercih edilmesi, ince ve karmaşık şekillerin kolayca elde edilmesi, yüksek boyutsal hassasiyet, metal ve alaşımların imalatında geniş bir tercih yelpazesi ve ekonomik olması gibi avantajlardan kaynaklanmaktadır. Ayrıca magnezyumun çok iyi dökülebilir olması bu teknikleri daha da cazip kılmaktadır. Özellikle otomotiv endüstrisinin gereksinim duyduğu hafif ve karmaşık kesitli parçaların imalatı döküm metotları ile elde edilebilir (Fink, 2003, Kumar ve ark., 2015). Diğer taraftan bu yöntemlerin, içyapıda gözenek oluşumu, kaba tane boyutu, kısa kalıp ömrü ve üretim sonrası mamule 
1sıl işlem uygulamalarının sınırlı olması gibi sakıncaları da bulunmaktadır. Magnezyum ve alaşımları döküm teknikleri haricinde dövme olarakta sarf edilmektedir. Fakat düşük süneklilik bu malzemeler için ciddi bir dezavantaj teşkil etmektedir. Bu nedenle dövme alaşımların kullanımı yıllık küresel tüketimin \%1'den dahi daha az teşekkül etmektedir. Birçok dövme alaşım 1sıl işlemlere tabi tutularak kullanılmaktadır. Özellikle pekleşme sertleşmesinin ardından ya ısıl işlem uygulanmaksızın ya da T5 sıcaklığında yapılan yaşlandırma işlemi ile mekanik özellikler iyileştirilerek tüketim hacimleri artırılmaktadır. Magnezyum ve alaşımlarının diğer pekçok metal ve alaşım gibi mekanik özellikleri bileşim, imalat tekniği ve 1sıl işlem türüne bağlı olarak değişiklik gösterse de bu etkenlerden üretim yöntemi (döküm veya dövme) aynı bileşimlerde dahi makanik özelliklerde önemli değişikliklere yol açmaktadır (Stevenson, 1991, Buldum ve ark., 2012, Javaid ve ark., 2014). Çizelge III' te ticari öneme sahip döküm ve dövme alaşımlar, Çizelge IV ve $V^{\prime}$ te ise bu malzemelerin kimyasal bileşimi ve oda sıcaklığı mekanik özellikleri sırası ile verilmiştir. Bu grafiklerden de görülebileceği üzere magnezyum alaşımlarının mukavemeti alüminyum alaşımlarına kıyasla biraz düşük olmasına rağmen spesifik dayanımları aynıdır. Magnezyum döküm alaşımları alüminyum döküm alaşımlarına nazaran taşıt ağırlığında ciddi kazanımlar sağlarken magnezyum dövme alaşımları ise alüminyum dövme alaşımları ile kıyaslanabilecek seviyede iyi dayanıma sahiptir (Mallick, 2012).

Çizelge III. Ticari öneme sahip magnezyum döküm ve dövme alaşımları (Stevenson, 1991, Jayasathyakawin ve ark., 2020 ).

\begin{tabular}{|c|c|}
\hline \multicolumn{2}{|l|}{ Magnezyum Alaşımları } \\
\hline Döküm & Dövme \\
\hline -Mg-Al-Mn alaşımları, örneğin; AM100A & -Mg-Al-Zn alaşımları, örneğin; AZ80A \\
\hline -Mg-Al-Zn alaşımları, örneğin; AZ63A & -Mg-Th-Zr alaşımları, örneğin; HK31A \\
\hline -Mg-Zn-Zr alaşımları, örneğin; ZK51A & -Mg-Th-Mn alaşımları, örneğin; HM21A \\
\hline -Mg-RE-Zn-Zr alaşımları, örneğin; EZ33A & -Mg-Zn-Zr alaşımları, örneğin; ZK60A \\
\hline -Mg-RE-Ag-Zr alaşımları, örneğin; QE22QA (Th ilaveli veya ilavesiz) & -Mg-Zn-Cu alaşımları, örneğin; ZC71A \\
\hline \multicolumn{2}{|l|}{-Mg-Th-Zr alaşımları, örneğin; ZH62A (Zn ilaveli veya ilavesiz) } \\
\hline -Mg-Zn-Cu alaşımları, örneğin; ZC63A & \\
\hline
\end{tabular}

\section{Otomotiv Uygulamaları}

Magnezyumun otomobillerde kullanımı 1921 yilında Alman Chemische Fabrik Griesheim firması tarafından üretilen bir piston ile başlamaktadır. 1923'te magnezyum döküm parçalarının metalürjik özelliklerinin iyileşmesi otomotiv endüstrisindeki ilginin artmasına neden olmuştur. 1927 senesinde Adlerwerke şirketi ürettiği 20.000 taşıtın birçok aksamında magnezyum kullanmıştır. 1930'da magnezyum yarış arabalarında da tercih edilmeye başlanmış ve Maserati'nin krank mili ve transmisyon kutusu gibi birçok parçası magnezyumdan üretilmiştir (Blawert ve ark., 2004). 1931 y1lında General Motor, Chevrolair motorların karter imalatını magnezyum ile gerçekleştirmiştir. 1935'te Bugatti, 57SC serisinin karoserinde magnezyum levhalar kullanmıştır. 1938 senesinde Volkswagen, Beetle modelinde motor bloğu ve transmisyon kutusunu magnezyumdan yapmıştır. 1951'de Buick Le SabreDream'ın kaportası magnezyum plakalardan imal edilmiştir. (Luo, 2013, Alderman, 2013, Jayaraja ve ark., 2015). 1952 yılında Chrysler grubu tarafindan üretilen araçlarda birçok parça magnezyum dökümden meydana gelmiştir. 1967'de Fiat, jant yapımında magnezyum kullanmıştır. 1968 senesinde Porsche, altı silindirli taşıtların karterini magnezyumdan üretmiştir. 1971 yılında VW AG, magnezyum kullanımını sürekli artırarak tüketim miktarını 42.000 tona çıkarmıştır. Bu tarihten sonra içten yanmalı motorlarda servis şartları, su soğutmalı motorlarda korozyon teşekkülü ve alaşım elementlerinin ekonomik olmaması gibi 
nedenler magnezyum kullanımını durma noktasına getirmiştir (Esdaile, 2001, Powell, 2003, Juchmann, 2006). Magnezyumun otomobillerde kullanımı, otomotiv endüstrisinin fosil kökenli yakıt rezervlerinin korunması ve karayolları trafiğindeki karbondioksit salınımının asgari düzeye indirgenmesi amacıyla 1990'lı yılların sonunda aldığı gönüllü kararla tekrardan başlamıştır (Friedrich ve Schumann, 2001). Bu kararla otomotiv sektöründe magnezyum kullanımı hızla artmış, yıllık tüketim hacmi \%0.3 seviyelerinden \%15 düzeylerine kadar çıkmıştır. Ford, Chrysler ve General Motor gibi firmalar ürettikleri taşıtlarda toplam 14.282 ton magnezyum sarf etmiştir. Sonraki yıllarda Ford şirketi yıllık tüketim miktarını 8.258 tondan 12.000 tona yükseltmiştir. Böylece magnezyumun otomobillerde kullanımı 2 kg'a kadar ulaşmıştır. 2000 yılında tüketim artmaya devam ederek taşıt başına kullanım 3.6 $\mathrm{kg}$ seviyesine çıkmıştır. Magnezyum ve alaşımlarının gösterge paneli, direksiyon simidi, direksiyon kolonu ve braketleri gibi iç bileşenlerde alüminyum ve alaşımlarının yerine tercih edilmesi ile taşıt başına kullanım 4 kg düzeyine yükselmiştir (Lou ve ark., 1995, Cole ve Sherman, 1995, Lou 2002, Das, 2003, Li, 2004, Lou, 2014). Bu malzemelerin iç donanım uygulamalarında alüminyum alaşımlarının yerine tercih edilmesi ağırlıkta \%30 oranında bir azalma oluşmasını sağlayarak dünya çapında önemli kazanımlar edinmesine yol açmıştır. 2004'te iç donanım, güç aktarma organları ve yapısal bileşen gibi temel sistemlerde ortalama 120.000 ton magnezyum sarf edilmiştir. Sonraki yıllarda bu değerden daha fazlasının sadece iki ana sistemde kullanılacağı tahmin edilmektedir. Gelecekte magnezyum ve alaşımlarının otomobillerde uygulama sayısının artırılması ile taşıt başına kullanımın 40 kg'a kadar çıkacağı, araç ağırlığının ise 1200 kg'dan 900 kg'a düşeceği öngörülmektedir (Froes ve ark., 1998, Dobrzański ve ark., 2007, Dieringa ve ark., 2016).

Çizelge IV. Magnezyum döküm alaşımlarının kimyasal bileşimi ve mekanik özellikleri (Shearouse, 1987).

\begin{tabular}{|c|c|c|c|c|c|c|c|c|c|c|}
\hline \multirow{2}{*}{ Alaşım } & \multirow{2}{*}{$\begin{array}{c}\text { Isıl } \\
\text { İşlem } \\
\text { Türü * }\end{array}$} & \multicolumn{5}{|c|}{ Kimyasal Bileşim (\%) } & \multirow{2}{*}{$\begin{array}{c}\text { Akma } \\
\text { Mukavemeti } \\
\text { (MPa) }\end{array}$} & \multirow{2}{*}{$\begin{array}{c}\text { Çekme } \\
\text { Mukavemeti } \\
\text { (MPa) }\end{array}$} & \multirow{2}{*}{$\begin{array}{c}\text { Süneklik } \\
(\%)\end{array}$} & \multirow{2}{*}{$\begin{array}{c}\text { Sertlik (Brinell) } \\
\text { HB }\end{array}$} \\
\hline & & Al & $\mathbf{Z n}$ & $\begin{array}{c}\text { Mn } \\
\text { min. }\end{array}$ & $\mathbf{Z r}$ & Diğerleri & & & & \\
\hline AM100A & $-\mathrm{T} 6$ & 10.0 & & 0.10 & & & 152 & 276 & 1 & 70 \\
\hline \multirow[t]{4}{*}{ AZ63A } & $-F$ & 6.0 & 3.0 & 0.15 & & & 97 & 200 & 6 & 50 \\
\hline & $-\mathrm{T} 4$ & & & & & & 90 & 276 & 12 & 55 \\
\hline & $-\mathrm{T} 5$ & & & & & & 97 & 207 & 4 & 55 \\
\hline & -T6 & & & & & & 131 & 276 & 5 & 73 \\
\hline AZ81A & -T4 & 7.5 & 0.7 & 0.13 & & & 83 & 276 & 15 & 55 \\
\hline \multirow[t]{4}{*}{ AZ91E } & $-F$ & 8.7 & 0.7 & 0.17 & & & 97 & 165 & 2 & 52 \\
\hline & $-\mathrm{T} 4$ & & & & & & 83 & 276 & 14 & 53 \\
\hline & $-\mathrm{T} 5$ & & & & & & 117 & 179 & 3 & \\
\hline & $-\mathrm{T} 6$ & & & & & & 131 & 276 & 5 & 66 \\
\hline \multirow[t]{4}{*}{ AZ92A } & $-\mathrm{F}$ & 9.0 & 2.0 & 0.10 & & & 97 & 165 & 2 & 65 \\
\hline & -T4 & & & & & & 97 & 276 & 9 & 63 \\
\hline & -T5 & & & & & & 110 & 179 & 2 & 70 \\
\hline & $-\mathrm{T} 6$ & & & & & & 145 & 276 & 2 & 84 \\
\hline EZ33A & -T5 & & 2.5 & & 0.8 & $3.5 \mathrm{RE}+$ & 103 & 159 & 3 & 50 \\
\hline K1A & $-F$ & & & & 0.7 & & 48 & 172 & 19 & \\
\hline \multirow[t]{2}{*}{ QE22A } & $\begin{array}{l}\mathrm{T} 6 \\
\end{array}$ & & & & 0.7 & $2.0 \mathrm{RE}, \vec{t}$ & 207 & 276 & 4 & \\
\hline & & & & & & $2.5 \mathrm{Ag}$ & & & & \\
\hline ZE41A & -T5 & & 4.0 & & 0.7 & $1.3 \mathrm{RE}+$ & 138 & 207 & 3.5 & 62 \\
\hline ZK51A & -T5 & & 4.5 & & 0.8 & & 165 & 276 & 8 & 65 \\
\hline ZK61A & -T6 & & 6.0 & & 0.8 & & 193 & 310 & 10 & 70 \\
\hline AZ91D & $-\mathrm{F}$ & 9.0 & 0.7 & 0.15 & & & 158 & 234 & 3 & 75 \\
\hline AM60B & $-F$ & 6.0 & 0.22 & 0.24 & & & 131 & 220 & $6-8$ & 62 \\
\hline AM50A & $-\mathrm{F}$ & 5.0 & 0.22 & 0.26 & & & 124 & 220 & $8-10$ & 57 \\
\hline AS41B & $-\mathrm{F}$ & 4.2 & 0.12 & 0.35 & & $1.0 \mathrm{Si}$ & 124 & 214 & 6 & 75 \\
\hline$\overline{\mathrm{AE} 42 \mathrm{X} 1}$ & $-\mathrm{F}$ & 4.0 & 0.22 & 0.25 & & $2.4 \mathrm{RE} \dagger$ & 138 & 228 & $8-10$ & 57 \\
\hline
\end{tabular}

* $\mathrm{F}=$ Üretildiği gibi, $\mathrm{T} 4=$ Yapay Yaşlandırma, $\mathrm{T} 5=$ Çözeltiye alma 1sıl işlemi, $\mathrm{T} 6=$ Çözeltiye alma 1sıl işlemi, $\uparrow$ Nadir Toprak Element Karı̧̧ımları 
Magnezyum ve Alaşımlarının Otomotiv Endüstrisindeki Önemi ve Uygulamaları

Çizelge V. Magnezyum dövme alaşımlarının kimyasal bileşimi ve mekanik özellikleri (Shearouse, 1987).

\begin{tabular}{|c|c|c|c|c|c|c|c|c|c|}
\hline \multirow{2}{*}{$\begin{array}{l}\text { Alaşım ve } \\
\text { Isıl işlem } \\
\text { Türü * }\end{array}$} & \multicolumn{4}{|c|}{ Kimyasal Bileşim (\%) } & \multirow{2}{*}{$\begin{array}{c}\text { Akma } \\
\text { Mukavemeti } \\
\text { (MPa) }\end{array}$} & \multirow{2}{*}{$\begin{array}{c}\text { Çekme } \\
\text { Mukavemeti } \\
\text { (MPa) }\end{array}$} & \multirow{2}{*}{$\begin{array}{c}\text { Basma } \\
\text { Mukavemeti } \\
\text { (MPa) }\end{array}$} & \multirow{2}{*}{$\begin{array}{c}\text { Süneklik } \\
(\%)\end{array}$} & \multirow{2}{*}{$\begin{array}{c}\text { Sertlik } \\
\text { (Brinell) } \\
\text { HB }\end{array}$} \\
\hline & Al & Mn & $\mathbf{Z n}$ & $\mathbf{Z r}$ & & & & & \\
\hline \multicolumn{10}{|c|}{ Çubuk/Profil } \\
\hline AZ31B-F & 3.0 & & 1.0 & & 200 & 262 & 97 & 15 & 49 \\
\hline AZ61A-F & 6.5 & & 1.0 & & 228 & 310 & 131 & 16 & 60 \\
\hline AZ80A-T5 & 8.5 & & 0.5 & & 276 & 379 & 241 & 7 & 82 \\
\hline ZK60A-F & & & 5.7 & 0.5 & 262 & 338 & 228 & 14 & 75 \\
\hline -T5 & & & 5.7 & 0.5 & 303 & 365 & 248 & 11 & 82 \\
\hline \multicolumn{10}{|c|}{ Boru } \\
\hline AZ31B-F & 3.0 & & 1.0 & & 165 & 248 & 83 & 16 & 46 \\
\hline AZ61A-F & 6.5 & & 1.0 & & 165 & 283 & 110 & 14 & 50 \\
\hline ZK60A-F & & & 5.7 & 0.5 & 241 & 324 & 172 & 13 & 75 \\
\hline$-\mathrm{T} 5$ & & & 5.7 & 0.5 & 276 & 345 & 207 & 11 & 82 \\
\hline M1A & & 1.2 & & & 179 & 255 & 83 & 11 & \\
\hline \multicolumn{10}{|c|}{ Levha } \\
\hline AZ31B-H24 & 3.0 & & 1.0 & & 221 & 290 & 179 & 15 & 73 \\
\hline & & & & & 200 & 276 & 159 & 17 & \\
\hline & & & & & 186 & 269 & 131 & 19 & \\
\hline AZ31B-O & 3.0 & & 1.0 & & 152 & 255 & 110 & 21 & 56 \\
\hline M1A & & 1.2 & & & 179 & 255 & 83 & 11 & \\
\hline \multicolumn{10}{|c|}{ Plaka } \\
\hline AZ31B & 3.0 & & 1.0 & & 131 & 241 & 69 & 12 & \\
\hline \multicolumn{10}{|c|}{ Sac } \\
\hline AZ31B & 3.0 & & 1.0 & & 131 & 241 & 76 & 14 & 52 \\
\hline
\end{tabular}

* F= Üretildiği gibi, H24= Gerinim sertleştirilmiş, Kısmi Tavlanmış, O= Tavlamış, T5= Yapay Yaşlandırılmış
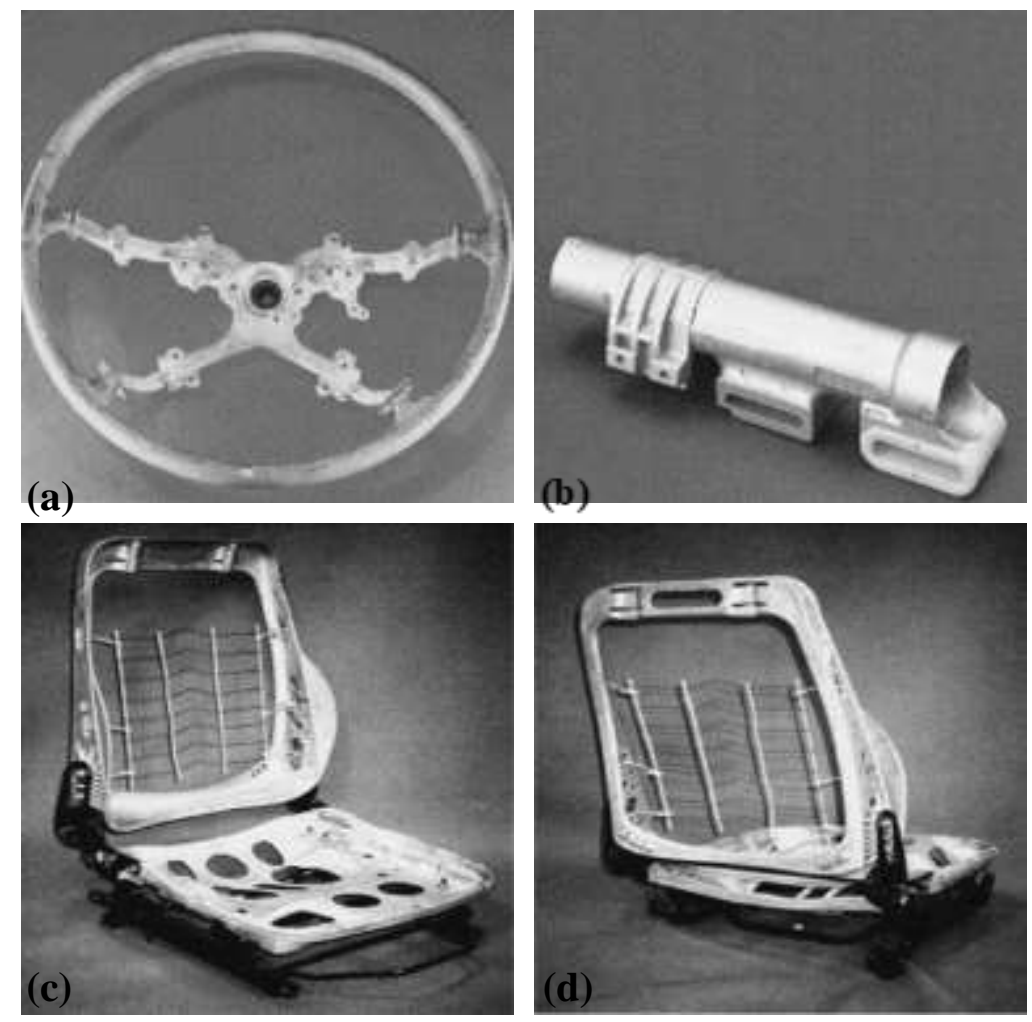

Şekil 3. Magnezyum ve alaşımlarından imal edilmiş iç donanım bileşenleri; a-b) Direksiyon simidi, direksiyon kolonu ve braketleri, c-d) Koltuk çerçevesi (Fink, 2003, Schumann ve Friedrich, 2006).

\section{İç donanım}

$\mathrm{Bu}$ malzemeler iç bileşenlerde gösterge paneli, dirsek destek tutucusu, koltuk çerçevesi, koltuk yükseltici, koltuk teknesi, konsol dayanağı, airbag kutusu, orta konsol kapağı, direksiyon simidi, anahtar gövdesi, direksiyon kolonu ve braketleri, radyo kutusu, torpido kapağı vb. birçok parça imalatında kullanılmaktadır. Magnezyumdan üretilen bu parçalardan direksiyon simidi $0.9 \mathrm{~kg}$, direksiyon mili 1.4 
$\mathrm{kg}$, koltuk çerçevesi ve gösterge paneli ise $1.8 \mathrm{~kg}$ olup, bunlar ağırlıkta çelik versiyonlarına kıyasla sırasıyla \%33, \%40 ve \%64 oranlarında önemli bir kazanım sağlamaktadır (Kulekci, 2008, Luo, 2013). Mercedes Benz ve Alfa Romeo gibi firmalar Roadster ve 156 modellerinde koltuk çerçevelerini tamamen magnezyumdan yapmakta ve bunlar yaklaşık olarak $2 \mathrm{~kg}$ ağırlıktan oluşmaktadır. Diğer taraftan magnezyumdan üretilen direksiyon kolonu ve braketlerinde ise geleneksel malzemelere kiyasla ağırlıkta ortalama 20 kg'lık bir hafifleme meydana gelmektedir (Jambor ve Beyer, 1997, Mus, 1998, Fink, 2003). Şekil 3'de magnezyum ve alaşımlarından imal edilen direksiyon simidi, direksiyon kolonu ve braketleri ve koltuk çerçevesi gibi iç donanım bileşenleri görülmektedir.

\section{Karoseri}

General Motor, Porsche AG ve Volkswagen AG gibi firmalar ürettikleri otomobillerin karoserisinde magnezyum levhalar kullanmaktadır. Şekil 4'te General Motor ve Volkswagen AG tarafından imal edilen kapı iç sacı, bagaj kapağı ve motor kaputu gibi karoseri bileşenleri görülmektedir. Bunlardan bagaj kapağı paneli çelik ve alüminyum versiyonlarına göre sırasıyla $\% 75$ ve \%33 daha hafiftir. Porsche AG, 911 GT3 RS yeni model otomobilinde magnezyum levhalar tercih etmiştir. Bir önceki modelde alüminyum levhalar kullanılmış ancak magnezyum levhaların en ince, en dayanıklı ve en hafif olduğu belirlenmiştir. Bu model alüminyum versiyonlarına kıyasla dahi \%30 daha hafif olup ağırlıkta önemli kazanımlar edinilmesini sağlamıştır. Volkswagen AG, Lupo otomobilinde hafif metal içeriğini \%18 artırarak, bagaj kapağı yapımında magnezyum levhalar kullanmıştır. Böylece ağırlıkta 5.1 kg'lık önemli bir azalma meydana gelmiştir. Ayrıca Super Light Car projesi kapsamında geliştirilen otomobil prototipinde karoseri bileşenlerinde magnezyum levhalar tercih edilerek ağırlıkta ortalama \%30 oranında bir kazanım elde edilmiştir (Mus, 1998, Goede ve ark., 2009, Stalmann ve ark., 2001, Lou ve Sachdev, 2012, Gupta, 2015, Anonymous, 2017, Chalisgaonkar, 2020).
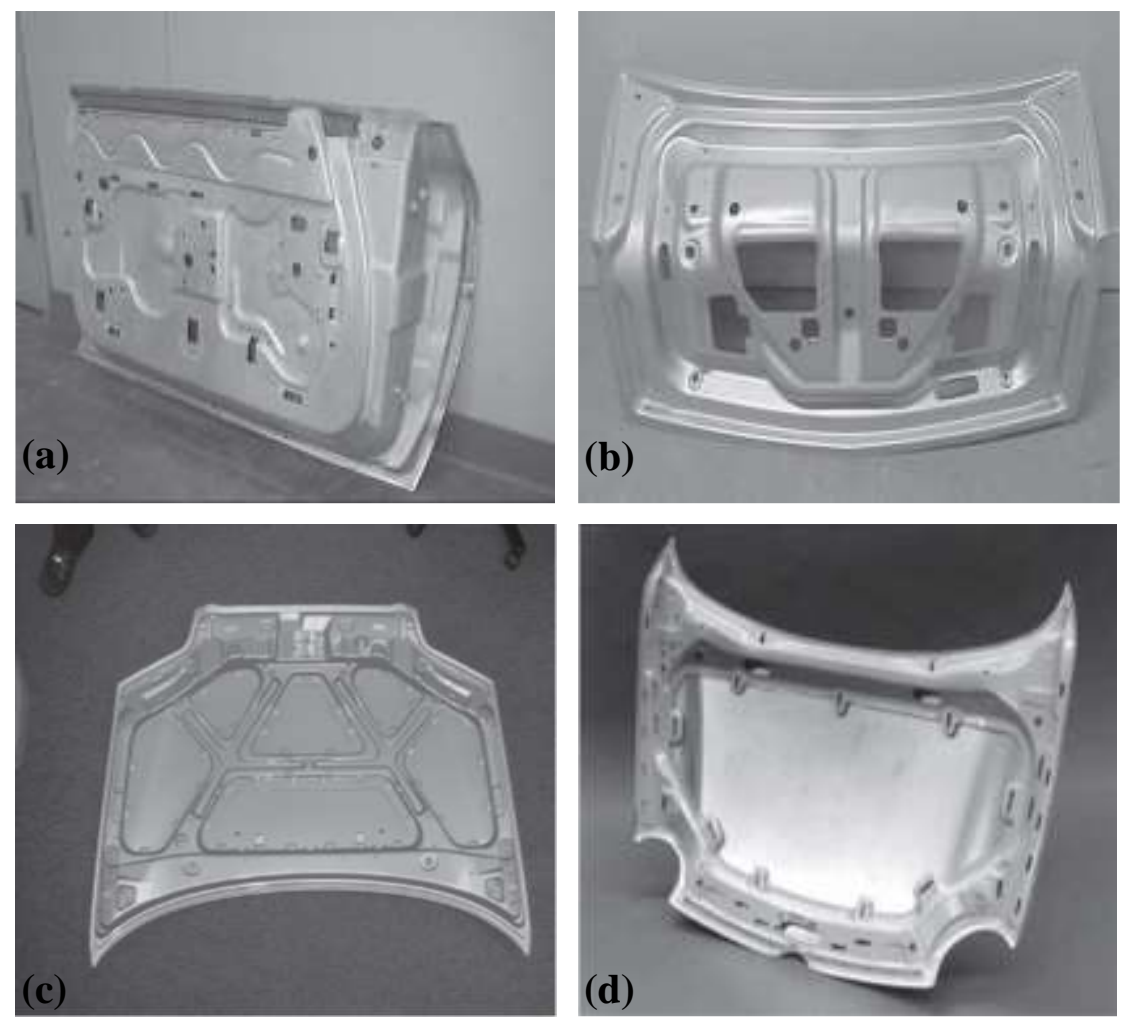

Şekil 4. Magnezyum ve alaşımlarından imal edilmiş koroseri bileşenleri; a) Kapı iç paneli, b) Bagaj kapağı, c-d) Motor kaputu (Lou ve Sachdev, 2012). 


\section{Şasi}

Volkswagen $\mathrm{AG}$, tarafindan üretilen ve geleceğin otomobili olarak gösterilen 1 litrelik taşıttın şasi üretiminde magnezyum profiller kullanılmıştır. Bu şasi uzay kafes sistemine sahip olup, toplam $76 \mathrm{~kg}$ ağırlıktan oluşmaktadır. Alüminyum versiyonlarına kıyasla $13 \mathrm{~kg}$ daha hafif olan bu araç $100 \mathrm{~km}$ mesafede 1 litre yakıt tüketmektedir. Şekil 5'te VW 1 litre otomobili ve uzay kafes şasi sistemi görülmektedir. Ayrıca magnezyum ve alaşımları tekerlek, ABS bağlantı parçaları, fren pedalı braketleri, gaz pedalı braketleri, fren pedalı kolu ve süspansiyon sistemi bağlantıları gibi şasi bileşenlerinde de tercih edilmektedir. Özellikle bu parçalardan tekerlek jantı yapımında uzun zamandan beri kullanılmaktadır. Porsche AG, tarafından 914 ve 944 modelleri için magnezyum döküm ile imal edilen tekerlek jantları $4.4 \mathrm{~kg}$ ve $5.9 \mathrm{~kg}$ ağırlı̆̆ında olup, alüminyum versiyonlarına nazaran sirasıyla \%19 ve $\% 22$ daha hafiftir (Schumann ve Friedrich, 2006).

(a)

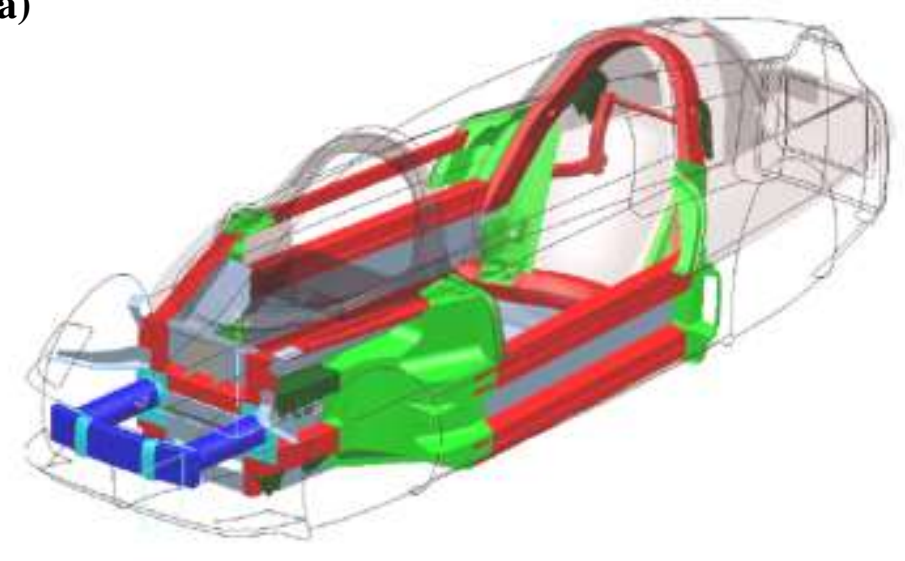

Alüminyum Profil

Alüminyum Lerha

Magnezyum Profil

Magnezyum Levha

Magnezyum Levha + Ị̇slenmiș

Magnezyum Levha + Yarı iṣlenmiş

Kompozit (Karbon Fiber Takviyeli)

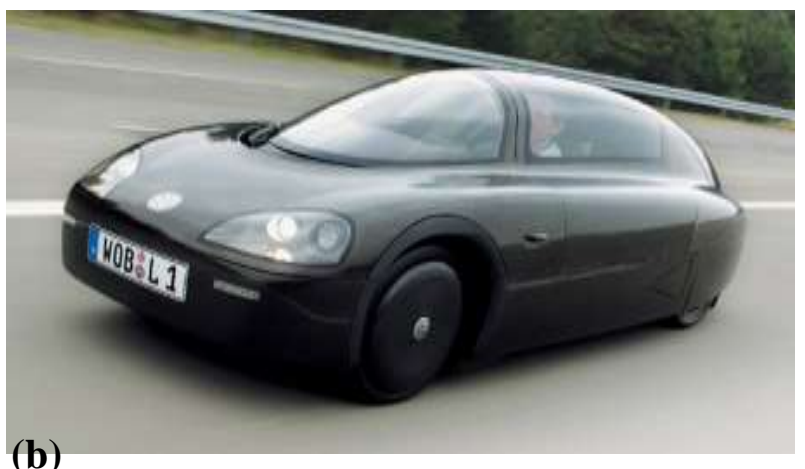

Şekil 5. VW 1 litrelik otomobil; a) Uzay kafes sistemi, b-c) ön ve iç görünümü (Schumann ve Friedrich, 2006).

\section{Güç aktarma organları}

BMW, Mercedes Benz ve Honda gibi şirketler silindir bloğu, transmisyon kutusu ve karter gibi güç aktarma organları bileşenlerinde magnezyum ve alaşımlarını tercih etmektedir. BMW tarafından üretilen ve toplam ağırlığın üçte biri oranında magnezyum içeren silindir bloğu alüminyum versiyonlarına kıyasla ağırlıkta 10 kg'lık bir kazanç sağlamaktadır. Honda firmasının imal ettiği karter ise alüminyum modellerine göre \%35 daha hafiftir. Ayrıca Magnezyum Güç Aktarma Organları Döküm Bileşenleri (MPCC) projesi kapsamında geliştirilen altı silindirli prototip blokta alüminyum versiyonlarına göre ağırlıkta \%25, karterde \%27, ön kapak ise \%53 oranında bir azalma meydana gelmiştir (Powell ve ark., 2010, Powell ve ark., 2012, Lou 2013). Bunların yanı sıra magnezyumdan üretilen motor kızağı ağırlıkta alüminyum modellerine kıyasla \%35 oranında bir kazanım sağlamaktadır (Jost, 2012). Şekil 6'da magnezyum ve alaşımlarından imal edilmiş silindir bloğu ve bileşenleri görülmektedir. 

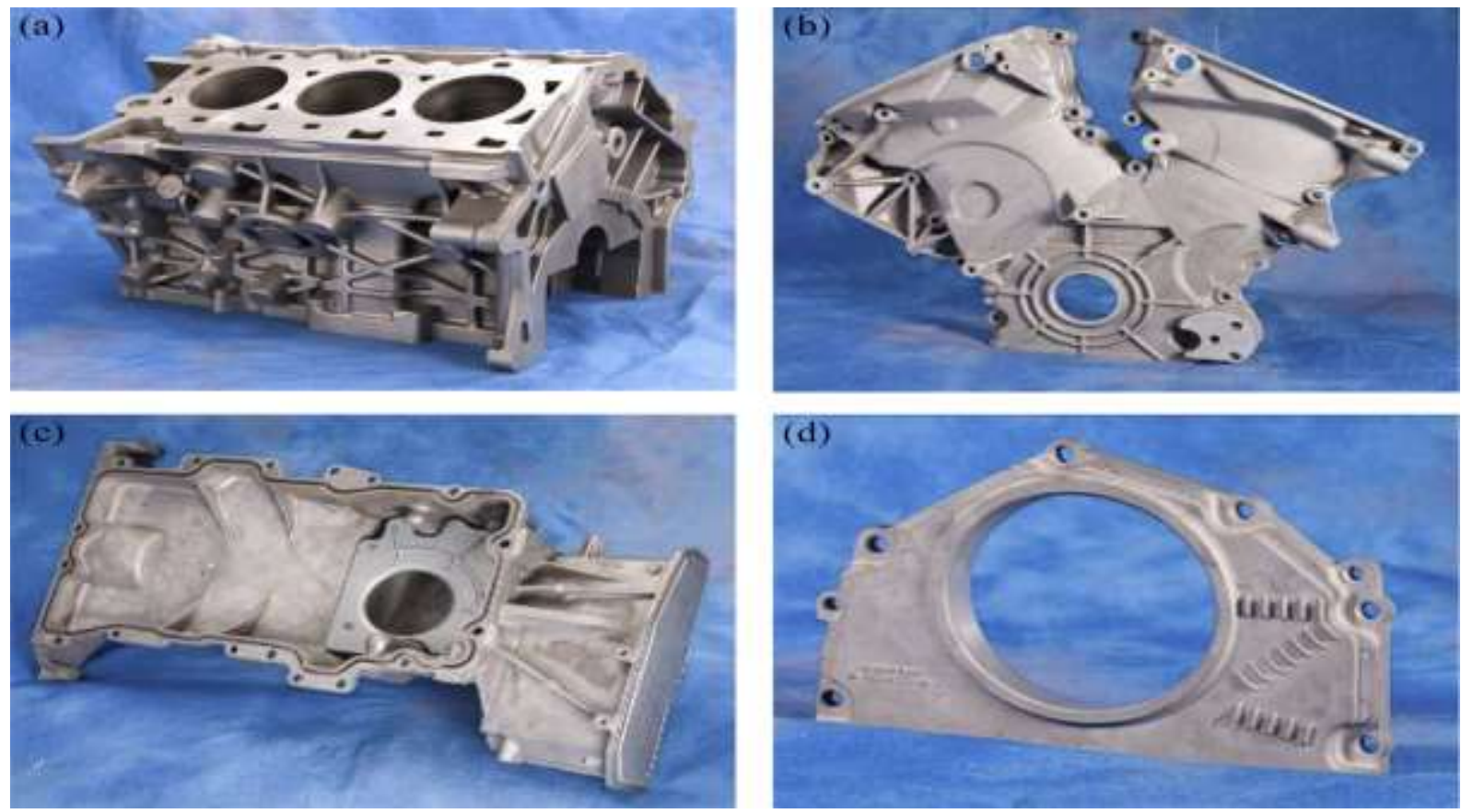

Şekil 6. Magnezyum ve alaşımlarından imal edilmiş silindir bloğu ve bileşenleri, a) Silindir bloğu, b) Motor kapağı-ön, c) Karter, d) Motor kapağı-arka (Luo, 2013).

(a)

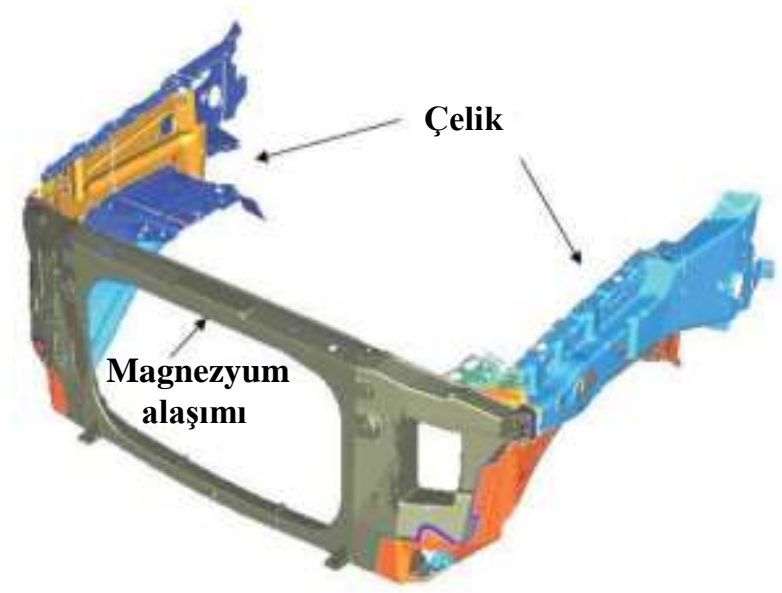

(b)

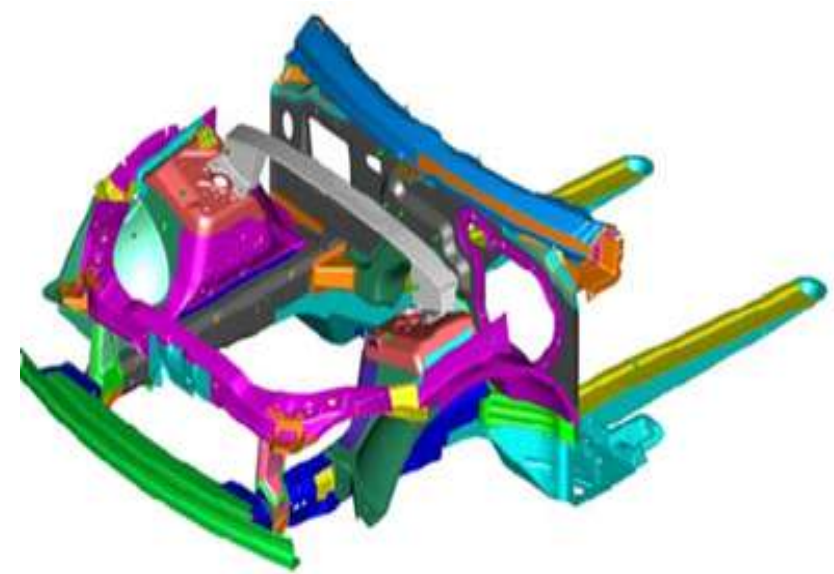

Şekil 7. a) Magnezyum alaşımı/Çelik içerikli ve b) Magnezyum yoğunluklu araç ön alanları (Lou ve ark., 2008, Jost, 2012). 


\section{Araç ön alanı}

İç donanım, karoseri, şasi ve güç aktarma organlarının yanı sıra magnezyum ve alaşımları araç ön alanında da yaygın olarak kullanılmaktadır. 2007 yılında Amerika Birleşik Devletleri (ABD), Çin Halk Cumhuriyeti ve Kanada gibi ülkeler tarafindan başlatılan Magnesium Front End Research \& Development (MFERD) projesi kapsamında araç ön alanında magnezyum kullanımının artırılması hedeflenerek ağırlığın \%60 oranında azaltılması amaçlanmıştır (Lou ve ark., 2008, Nyberg ve ark., 2008). Bu bağlamda Cadillac CTS ve Ford F150 taşıtların araç ön alanı kısmında magnezyum ve alaşımları yoğun olarak kullanılmıştır. Bu araçlardan Cadillac CTS lüks otomobillinin araç ön alanı çelik modellere göre 99.6 kg'dan 55.3 kg'a, parça sayıs1 da 110'dan 47'ye düşmüştür. Ford F150 hafif kamyonetinde ise ağırlık 57.1 kg'dan 42.9 kg'a parça sayısı da 20'den 18'e düşmüştür. CTS modelinde 44.3 kg'lık bir hafifleme ve parça sayısında da \%57.3 oranında bir azalma meydana gelirken F150'de ise ortalama \%25 oranında bir hafifleme ve parça sayısında da \%10'luk bir azalma sağlanmıştır (Li ve ark., 2005, Lou, 2011, Jost, 2012, Forsmark ve ark., 2014). Şekil 7'de magnezyum içerikli araç ön kısmının şematik görünümleri verilmiştir.

$\mathrm{Bu}$ malzemelerin otomotiv endüstrisinde tüketim hacimlerinin sürekli olarak artacağ1 otomobillerde $227 \mathrm{~kg}$ çeliğin ve $59 \mathrm{~kg}$ alüminyumun yerine kullanılarak taşıt ağırlı̆̆ında \%15 oranında bir hafifleme sağlanacağı öngörülmektedir (Berry, 2015, Wang ve ark., 2019). Çizelge VI' da magnezyum ve alaşımlarının otomobillerdeki mevcut uygulamaları verilmiştir.

Çizelge VI. Otomotiv Endüstrisinde Magnezyum Uygulamaları (Luo 2013).

\begin{tabular}{|c|c|c|c|c|}
\hline Sistemler & Bileşenler & $\begin{array}{l}\text { Kuzey } \\
\text { Amerika }\end{array}$ & Avrupa & $\overline{\text { Asya }}$ \\
\hline \multirow[t]{14}{*}{ İç donanım } & Gösterge Paneli & Var & Var & Var \\
\hline & Dirsek Destek Tutucusu & Var & ----- & ---- \\
\hline & Koltuk Çerçevesi & Var & Var & Var \\
\hline & Koltuk Yükseltici & Var & Var & Var \\
\hline & Koltuk Teknesi & Var & Var & ----- \\
\hline & Konsol Dayanağı & Var & ----- & ----- \\
\hline & Hava Yastığg Kutusu & Var & ----- & ----- \\
\hline & Orta Konsol Kapağı & ----- & Var & ----- \\
\hline & Direksiyon Simidi & Var & Var & Var \\
\hline & Anahtar Gövdesi & Var & ----- & ----- \\
\hline & Direksiyon Mili Parçaları & Var & Var & Var \\
\hline & Radyo Kutusu & Var & ----- & ---- \\
\hline & Torpido Kapağ1 & Var & ----- & ----- \\
\hline & Cam Motoru Muhafazası & Var & Var & ----- \\
\hline \multirow[t]{8}{*}{ Karoseri } & Kapı Çerçevesi & ----- & Var & ----- \\
\hline & Arka Panel & Var & Var & ----- \\
\hline & Tavan Çerçevesi & Var & Var & ----- \\
\hline & Açılır Tavan Paneli & Var & Var & ----- \\
\hline & Ayna Braketleri & Var & Var & ----- \\
\hline & Yakıt Deposu Kapağı & ----- & Var & ----- \\
\hline & Kapı Kolları & ----- & Var & Var \\
\hline & Yedek Lastik Yuvası & ----- & ----- & ----- \\
\hline \multirow[t]{6}{*}{ Şasi } & Tekerlek (Yarış) & Var & Var & Var \\
\hline & ABS Bağlantı Parçası & Var & ----- & ----- \\
\hline & Fren Pedalı Bağlantı Parçası & Var & ----- & Var \\
\hline & Fren/Gaz Pedalı Braketi & Var & ---- & ---- \\
\hline & Fren/Debriyaj Braketi & Var & ----- & ----- \\
\hline & Fren Pedalı Kolu & Var & ----- & ----- \\
\hline \multirow[t]{11}{*}{ Güç Aktarma Organları } & Silindir Bloğu & ----- & Var & ----- \\
\hline & Külbütör/Eksantrik Kapağ1 & Var & Var & Var \\
\hline & Kardan Kutusu & Var & ----- & ----- \\
\hline & Transmisyon Kutusu & ----- & Var & Var \\
\hline & Kavrama Kutusu ve piston & Var & ----- & ----- \\
\hline & Emme Manifoldu & Var & Var & ----- \\
\hline & Karter & ----- & Var & Var \\
\hline & Alternatör/AC Braketi & Var & ----- & ----- \\
\hline & Transmisyon & Var & ----- & ----- \\
\hline & Yağ Filtresi Adaptörü & Var & ----- & Var \\
\hline & Elektrikli Motor Muhafazası & Var & ----- & ----- \\
\hline
\end{tabular}




\section{SONUÇ}

Egzoz emisyon değerlerine getirilen yasal sınırlamalar sonucu taşıt ağırlığını azaltma gereksinimi otomotiv endüstrisini modern hafif yapılara yönlendirmiştir. Ayrıca güvenlik, konfor ve yüksek performans talepleri otomobil ağırlığını artırmış bu durum hafif malzeme kullanımını kaçınılmaz kılmıştır. Magnezyum ve alaşımları düşük yoğunluk, yüksek özgül dayanım, kolay geri kazanım ve mükemmel sönümleme kapasitesi gibi üstün özellikleri ile otomotiv uygulamaları için önemli bir potansiyel oluşturmaktadır. Bu malzemelerin otomobillerde yüksek sıcaklık ve gerilmelere maruz kalmayan birçok uygulaması bulunmasına karşın asıl kullanım alanlarının taşıt ağırlığının önemli bir kısmını oluşturan motor bloğu, silindir kapağı, vites ve diferansiyel kutusu gibi güç aktarma organları bileşenleri olacağı öngörülmektedir. Fakat yüksek sıcaklık dayanımlarının düşük olması, yetersiz sürünme dirençleri, zayıf korozyon dayanımları ve oda sıcaklığında gözlenen düşük süneklikleri yüksek performans gerektiren bu uygulamalardaki kullanımlarını sınırlamaktadır. Bu nedenle magnezyum ve alaşımlarının yapısal ve fonksiyonel özelliklerinin iyileştirilmesi büyük önem arz etmektedir. Özellikle düşük maliyetli, yüksek performanslı ve mükemmel korozyon dayanımlı alaşım ve kompozitlerin geliştirilmesi sektörün başlıca beklentisi olmuştur. Bu bağlamda magnezyum ve alaşımlarının düşük mekanik özellikleri ve zayıf korozyon dayanımı alaşımlama veya kompozit malzeme yaklaşımları ile bertaraf edilerek güç aktarma organları ve diğer temel sistemlerdeki uygulama sayıları artırılmalıdır. Böylece otomobil ağırlığında elde edilecek önemli hafifleme ile hem fosil kökenli yakıt rezervlerinin korunması hem yakıt verimliliğinin iyileştirilmesi hem de insan sağlı̆̆ı ve çevre kalitesi açısından son derece ciddi sorunlar teşkil eden egzoz emisyonlarının minimize edilmesi sağlanmalıdır.

\section{KAYNAKLAR}

Aghion E, Golub G, 2006. Production Technologies of Magnesium. Magnesium Technology Springer-Verlag, pp. 29-60, Berlin, Germany.

Alderman M, 2013. Magnesium:The Lightest Structural Metal in Automotive, Magnesium Elektron, http://www.global-automotive-lightweight-materials.com (Erişim Tarihi:10.12.2018).

Anonymous, 2017. Mass-Produced Magnesium Porsche Uses POSCO's Mass-produced Magnesium Sheets in New Model Roof, http://www.businesskorea.co.kr/english/news (Erişim Tarihi: 18.10.2019).

Baril E, Labelle P, Pekguleryuz M, 2003. Elevated temperature Mg-Al-Sr: creep resistance, mechanical properties, and microstructure, JOM Journal of the Minerals, 55 (11): 34-39.

Berry C, 2015. A Closer Look at Magnesium, Zimtu research - the power of insight, Canada, https://rockstoneresearch.com/images/PDF (Erişim Tarihi:14.10.2019).

Blawert C, Hort N, Kainer K.U, 2004. Automotive Applications of Magnesium and Its Alloys. Trans. IndianInst. Met, 57 (4): 397-408.

Blum W, Watzinger B, Zhang P, 2000. Creep of Die-Cast Light-Weight Mg-Al base Alloy AZ91hp, Advanced Engineering Materials, 2(6): 349-355.

Buldum B. B, S1k A, Ozkul I, 2012. Investigation of magnesium alloys machinability, International Journal of Electronics, 2(3): 261-268.

Chalisgaonkar R, 2020. Insight in applications, manufacturing and corrosion behaviour of magnesium and its alloys-A review, Materials Today: Proceedings.

Cole G. S, Sherman A. M, 1995. Light weight materials for automotive applications. Materials characterization, 35 (1): 3-9.

Das S, 2003. Magnesium for automotive applications: Primary production cost assessment, JOM Journal of the Minerals. Metals and Materials Society, 55 (11): 22-26.

Davis J, 1991. The potential for vehicle weight reduction using magnesium. SAE Technical Paper 910551, 1-17.

Dieringa H, Bohlen J, Hort N, Letzig D, Kainer K. U, 2016. Advances in manufacturing processes for magnesium alloys. Essential Readıngs In Magnesium Technology, pp 19-25, USA. 
Dobrzanski L.A, Tanski T, Cížek L, 2005. Influence of modification with chemical elements on structure of magnesium casting alloys. 13th Scientific International Conferences, Achievements in Mechanical and Materials Engineering AMME, 2005, pp. 199-202

Dobrzański L. A, Tański T, Č́žžek L, Brytan Z, 2007. Structure and properties of magnesium cast alloys. Journal of Materials Processing Technology, 192-193, 567-574.

Eliezer D, Aghion E, Froes F. S, 1998. Magnesium science, technology and applications. Advanced Performance Materials, 5(3): 201-212.

Esdaile R.J, 2001. Magnesium Casting Applications in the Automotive Industry. SAE Technical Paper 2001-010415, 1-7.

Fink R, 2003. Die Casting Magnesium, Magnesium Alloys and Technology, pp. 23-44, Germany,

Forsmark J. H, Li M, Su X, Wagner D. A, Zindel J, Luo A. A, Quinn J. F, Verma R, Wang Y. M, Logan S. D, Bilkhu S, McCune R. C, 2014. The USAMP Magnesium Front End Research and Development ProjectResults of the Magnesium "Demonstration” Structure, In Magnesium Technology, Springer, pp. 517-524, USA.

Friedrich H, Schumann S, 2001. Research for a "new age of magnesium" in the automotive industry. Journal of Materials Processing Technology, 117 (3): 276-281.

Froes F. H, Eliezer D, Aghion E, 1998. The science, technology, and applications of magnesium. JOM Journal of the Minerals, Metals and Materials Society, 50 (9): 30-34.

Gaines L, Cuenca R, Stodolsky F, Wu S, 1996. Potential automotive uses of wrought magnesium alloys (No: ANL/ES/CP-89958; CONF-9604136-21), Argonne National Lab, IL 60439, USA.

Ghassemieh E, 2011. Materials in Automotive Application, State of the Art and Prospects. New Trends and Developments in Automotive Industry, In Tech, ISBN: 978-953-307-999-8, pp. 365-394, UK.

Goede M, Stehlin M, Rafflenbeul L, Kopp G, Beeh E, 2009. Super Light Car-lightweight construction thanks to a multi-material design and function integration. European Transport Research Review, 1(1): 5-10.

Gupta M, 2015. Advanced lightweight magnesium based materials in marine engineering. Innovation \& Cooperation in Naval Architecture \& Marine Engineering Alliance, ICNAME, China.

Han Q, Kad B. K, Viswanathan S, 2004. Design perspectives for creep-resistant magnesium die-casting alloys, Philosophical Magazine, 84 (36): 3843-3860.

Hanko G, Antrekowitsch H, Ebner P, 2002. Recycling automotive magnesium scrap. JOM Journal of the Minerals, Metals and Materials Society, 54 (2): 51-54.

Harbodt K, 2006. History until 1945. Magnesium Technology Springer-Verlag, pp. 1-12, Berlin, Germany.

Hussein R. O, Northwood D. O, 2014. Improving the performance of magnesium alloys for automotive applications, WIT Transactions on the Built Environment, 137, 531-544.

Jambor A, Beyer M, 1997. New cars-new materials, Materials \& design, 18 (4): 203-209.

Javaid A, Czerwinski F, Zavadil R, Aniolek M, Hadadzadeh A, 2014. Solidification characteristics of wrought magnesium alloys containing rare earth metals, Magnesium Technology, The Minerals, Metals and Materials Society (TMS), pp. 197-202, USA.

Jayaraja J, Prasanth M, Srinivasan, A, Pillai, U. T. S, Pai1, B. C, 2015. Magnesium in Indian Context. Indian Foundry Journal, 61(2): 49-55.

Jayasathyakawin S, Ravichandran M, Baskar N, Chairman C. A, Balasundaram R, 2020. Mechanical properties and applications of Magnesium alloy-Review. Materials Today: Proceedings.

Joost W. J, 2012. Reducing vehicle weight and improving US energy efficiency using integrated computational materials engineering. Jom, Journal of the Minerals, Metals and Materials Society, 64 (9): 1032-1038.

Joost W.J, Krajewski P.E, 2017. Towards magnesium alloys for high-volume automotive applications. Scripta Materialia, 128, 107- 112.

Juchmann P, 2006. Forming, Magnesium Technology, pp. 269-289, Berlin, Germany.

Kainer K. U, Von Buch F, 2003. The current state of technology and potential for further development of magnesium applications. Magnesium-Alloys and Technology, pp. 1-22, Germany. 
King J. F, 2006. Alloys Containing Zirconium, Magnesium Technology, Springer-Verlag, pp. 128-144, Berlin, Germany.

Kulekci M. K, 2008. Magnesium and its alloys applications in automotive industry. The International Journal of Advanced Manufacturing Technology, 39 (9): 851-865.

Kramer D. A, 2001. Magnesium, Its Alloys and Compounds, U.S. Geological Survey Publication, 1(341): 1-30.

Kumar D, Phanden R. K, Thakur L, 2020. A review on environment friendly and lightweight Magnesium-Based metal matrix composites and alloys, Materials Today: Proceedings.

Kumar D. S, Sasanka C. T, Ravindra K, Suman K. N. S, 2015. Magnesium and its alloys in automotive applications-a review, American Journal of Materials Science and Technology, 4(1): 12-30.

Leil T. A, Hort N, Dietzel W, Blawert C, Huang Y, Kainer K. U, Rao K. P, 2009. Microstructure and corrosion behavior of Mg-Sn-Ca alloys after extrusion, Transactions of Nonferrous Metals Society of China, 19(1): 40-44.

Li G. H, Gill H. S, Varin R. A, 1993. Magnesium Silicide Intermetallic Alloys, Metallurgical Transactions A, 24(11), 2383-2391.

Li N, 2004. Automotive Magnesium Applications and Life Cycle Environmental Assessment, The 3rd International Conference on SF6 and the Environment, Michigan, December 1-3, pp. 1-26.

Li N, Osborne R, Cox B, Penrod D, 2005. Magnesium Engine Cradle-The USCAR Structural Cast Magnesium Development. SAE Technical Paper 2005-01-0337, 79-88.

Li S, Yang X, Hou J, Du W, 2020. A review on thermal conductivity of magnesium and its alloys. Journal of Magnesium and Alloys, 8, 78-90.

Luo A. A, 2002. Magnesium: current and potential automotive applications. Jom Journal of the Minerals, Metals and Materials Society, 54 (2): 42-48.

Lou A. A, 2011. The USAMP Magnesium Front End Research and Development (MFERD), USAMP, https://energy.gov/sites/prod/files/2014/03/f11/lm008_luo_2011_o.pdf (Erişim Tarihi: 10.12. 2019).

Luo A. A, 2013. Applications: aerospace, automotive and other structural applications of magnesium. In Fundamentals of Magnesium Alloy Metallurgy, pp. 266-316, USA.

Luo A. A, 2014. Alloy Development, Manufacturing and Design for Magnesium Applications. Magnesium Technology, pp. 5-7, USA.

Luo A. A, Nyberg E. A, Sadayappan K, Shi W, 2008. Magnesium front end research and development: A CanadaChina-USA collaboration. Magnesium Technology, pp. 41-48, USA.

Luo A, Renaud J, Nakatsugawa I, Plourde J, 1995. Magnesium castings for automotive applications. JOM Journal of the Minerals, Metals and Materials Society, 47 (7): 28-31.

Luo A. A, Sachdev A. K, 2012. Applications of magnesium alloys in automotive engineering. In Advances in wrought magnesium alloys, pp. 393-426, UK.

Luo A, Pekguleryuz M. O, 1994. Cast magnesium alloys for elevated temperature applications, Journal of Materials Science, 29 (20): 5259-5271.

Mallick P. K, 2012. Advanced materials for automotive applications: an overview, In Advanced Materials in Automotive Engineering, Woodhead Publishing, pp. 5-27, UK.

Mendis C. L, Hono K, 2013. Understanding precipitation processes in magnesium alloys, Fundamentals of Magnesium Alloy Metallurgy, Woodhead Publishing, Philadelphia, pp. 125-151, USA.

McWilliams A, 2011. Lightweight materials in transportation, Rapor No: AVM056B, MA: BBC Research, Wellesley, USA.

Mordike B. L, Lukac P, 2006. Physical Metallurgy, Magnesium Technology, Springer-Verlag, pp. 63-109, Berlin, Germany.

Mordike, B. L, Von Buch, F, 2003. High-Temperature Properties of Magnesium Alloys, Magnesium-Alloys and Technology, Verlag, pp. 106-129, Weinheim, Germany.

Mus C, 1998. The today and future potential of magnesium in the automotive industry. Metallurgical Science and Tecnology, 15 (2): 62-66. 
Nyberg E. A, Luo A. A, Sadayappan K, Shi W, 2008. Magnesium for future autos. Advanced Materials \& Processes, 166 (10): 35-37.

Polmear I. J, 2006. Light alloys: from traditional alloys to nanocrystals, Fourth Edition, pp. 237-297, ButterworthHeinemann, UK.

Powell B. R, 2003. The USAMP Magnesium Powertrain Cast Components Project. The Journal of The Minerals, Metals \& Materials Society (TMS), 55(11): 28-29.

Powell B. R, Krajewski P. E, Luo A. A, 2010. Magnesium alloys for lightweight powertrains and automotive structures. In Materials, Design and manufacturing for lightweight vehicles, pp. 114-173, Cambridge, UK.

Powell B. R, Luo A. A, Krajewski P. E, 2012. Magnesium alloys for lightweight powertrains and automotive bodies, In Advanced Materials in Automotive Engineering, pp. 150-209, UK.

Powers W. F, 2000. Automotive materials in the 21st century. Advanced Materials \& Processes, 157 (5): 38-41.

Sankaranarayanan S, Gupta M, 2020. Emergence of god's favorite metallic element: Magnesium based materials for engineering and biomedical applications. Materials Today: Proceedings.

Schumann S, Friedrich H, 2006. Engineering requirements, strategies and examples. Magnesium Technology, Metallurgy, Design Data, Applications, Magnesium Technology, pp. 499-632, Berlin, Germany.

Schwam D, Wallace J. F, Zhu Y, Viswanathan S, Iskander S, 2000. Enhancements in Magnesium Die Casting Impact Properties, https://www.osti.gov/servlets/purl/803212. (Date of access: 16 November 2015)

Shearouse J. D, 1987. Magnesium and Magnesium Alloys, Nonferrous Metals and Alloys; Metallic Specialities, Materials of Engineering, Marks' Standard Handbook for Mechanical Engineers, Tenth Edition, pp. 6-93, New York, USA.

Smola B, Stulıková I, Pelcova J, Mordike B. L, 2004. Significance of stable and metastable phases in high temperature creep resistant magnesium-rare earth base alloys, Journal of Alloys and Compounds, 378 (12): 196-201.

Song J, She J, Chen D, Pan F, 2020. Latest research advances on magnesium and magnesium alloys worldwide. Journal of Magnesium and Alloys, 8, 1-41.

Stalmann A, Sebastian W, Friedrich H, Schumann S, Dröder K, 2001. Properties and processing of magnesium wrought products for automotive applications. Advanced Engineering Materials, 3 (12): 969-974.

Stevenson, A., 1991. Heat treating of magnesium alloys, ASM International, ASM Handbook, Volume 4, pp. 899906, Philadelphia, USA.

Sun Y. H, Wang R. C, Peng C. Q, Yan F, Ming Y, 2017. Corrosion behavior and surface treatment of superlight Mg-Li alloys, Transactions of Nonferrous Metals Society of China, 27 (7): 1455-1475.

Tang Y, Jia W, Liu X, Le Q, Cui J, 2017. Precipitation evolution during annealing of Mg-Li alloys, Materials Science and Engineering, A, 689, 332-344.

Wang J, Pang X, Jahed H, 2019. Surface protection of Mg alloys in automotive applications: A review, 6(4): 567600.

Wang L, Chen M, 2013. End-of-life vehicle dismantling and recycling enterprises: developing directions in China, JOM, 65 (8): 1015-1020.

Wang X. J, Xu D. K, Wu R. Z, Chen X. B, Peng Q. M, Jin L, Chen G, 2018. What is going on in magnesium alloys, Journal of Materials Science \& Technology, 34(2), 245-247.

Westengen H, Aune T, 2006. Magnesium casting alloys. Magnesium Technology, Magnesium Technology Springer-Verlag, pp. 145-166, Berlin, Germany.

Yim C. D, You B. S, Jang R. S, Lim S. G, 2006. Effects of melt temperature and mold preheating temperature on the fluidity of Ca containing AZ31 alloys, Journal of materials science, 41(8): 2347-2350.

Zhang Z, 2000. Development of Magnesium-Based Allovs for Elevated Temperature Applications, , Univ. Laval, Ph.D. Thesis (Printed) 